User acceptance of virtual reality: an extended technology acceptance model

Camille Sagnier ${ }^{\mathrm{a}^{*}}$, Emilie Loup-Escande ${ }^{\mathrm{a}^{*}}$, Domitile Lourdeaux ${ }^{\mathrm{b}}$, Indira Thouvenin $^{\mathrm{b}}$ and Gérard Valléry ${ }^{\mathrm{a}}$

${ }^{a}$ Center for Research on Psychology: Cognition, Psyche and Organizations (CRP-CPO EA 7273), University of Picardy Jules Verne, Amiens, France

${ }^{b}$ Sorbonne universités, Université de Technologie de Compiègne, CNRS UMR 7253

Heudiasyc, Compiègne, France

*Corresponding authors, e-mails: emilie.loup-escande@u-picardie.fr ;

camille.sagnier@u-picardie.fr 


\title{
User acceptance of virtual reality: an extended technology acceptance model
}

\author{
Although virtual reality (VR) has many applications, only few studies have \\ investigated user acceptance of this type of immersive technology. We propose \\ an extended version of the Technology Acceptance Model (TAM) that addresses \\ some aspects of VR. Our model includes variables from the TAM, user \\ experience, variables specific to VR, and variables relating to user characteristics. \\ This model was tested with 89 users who performed an aeronautical assembly \\ task in VR. Results suggest that intention to use VR is positively influenced by \\ perceived usefulness and negatively influenced by cybersickness. Hedonic \\ quality-stimulation and personal innovativeness are predictors of perceived \\ usefulness. Perceived ease of use does not have a significant impact on intention \\ to use and it is only influenced by pragmatic quality. These findings have a \\ number of implications regarding user acceptance of VR.
}

Keywords: virtual reality; virtual environments; user acceptance; technology acceptance model; user experience; cybersickness

\section{Introduction}

Virtual reality (VR) refers to the simulation of an interactive three-dimensional environment that users can be immersed into and that they can interact with (Muhanna, 2015). A wide variety of VR applications have been developed for the purposes of leisure (e.g., Yoon, Lee, \& Park, 2018), education (e.g., Lamb, Antonenko, Etopio, \& Seccia, 2018), training (e.g., Gavish et al., 2015), therapy (e.g., Freeman et al., 2016), and rehabilitation (e.g., Hsu et al., 2017).

A number of studies have focused on the usability of VR (e.g., Merchant et al., 2012; Ordaz, Romero, Gorecky, \& Siller, 2015; Sun, Sonka, \& Beichel, 2013), but few have used the Technology Acceptance Model (Davis, 1989) to study user acceptance of VR (e.g., Bertrand \& Bouchard, 2008) and of other virtual environments 
(e.g., Fetscherin \& Lattemann, 2008; Tokel \& İsler, 2013). Only few of these studies have included user characteristics into user acceptance models (e.g., personal innovativeness in the study by Kim \& Forsythe, 2008), even though several studies on non-immersive technologies show its effects, for example on perceived ease of use of email notifications (Serenko, 2008) or on perceived ease of use, perceived usefulness and continuance intention to use online check-in services of airline passengers (Lin \& Filieri, 2015).

One of the widely studied questions in HCI is user experience, but models of user experience have only rarely been combined with the Technology Acceptance Model (Hornbæk \& Hertzum, 2017). There have, however, been studies showing the pertinence of such combined models, such as in the context of a web-based encyclopedia (Van Schaik \& Ling, 2011) or a game console (Kauer, Theuerling, \& Bruder, 2013). To our knowledge, user experience and the Technology Acceptance Model have not yet been combined in the context of VR.

Moreover, user experience with immersive technologies has specific outcomes that makes it distinct from traditional technologies (Mütterlin \& Hess, 2017): it enables a feeling of presence and it can make users feel sick. For this reason, we believe that these two characteristics of user experience with VR, namely presence and cybersickness, must be included in user acceptance models of VR, besides more traditional variables of user experience. Several studies have already show an effect of presence in user acceptance of VR (e.g., presence in the study by Shin, Biocca, \& Choo, 2013) but without combining it with other traditional measures of user experience.

Our objective in the present work was to test an extended Technology Acceptance Model designed for studying user acceptance of VR. To fill the different 
gaps we identified in the literature on user acceptance of VR, the extended model we propose includes user experience variables, variables specific to VR, and user characteristics. The article is structured as follows. Section 2 provides an overview of the literature that enabled us to construct our research model via eight hypotheses. Section 3 explains the research methodology based on an experimental setup. Section 4 presents the results obtained, and Section 5 discusses what these might indicate. The article concludes with an assessment of the limitations of the present study, its implications, and our recommendations for future studies.

\section{Research model and hypotheses}

\section{Technology Acceptance Model}

Davis (1989) based the Technology Acceptance Model (TAM) on two psychosocial theories that seek to explain and predict a specified behavior: the Theory of Reasoned Action (Fishbein \& Ajzen, 1975) and the Theory of Planned Behavior (Ajzen, 1991). In the TAM, intention to use a given technology is predicted by two user perceptions: its perceived usefulness and its perceived ease of use. Perceived usefulness is defined as "the degree to which a person believes that using a particular system would enhance his or her job performance" (Davis, 1989, p. 320). Perceived ease of use refers to "the degree to which a person believes that using a particular system would be free of effort" (Davis, 1989, p. 320). Several works have shown that perceived usefulness is the strongest predictor of intention to use. In a meta-analysis, King and He (2006) reported a mean $\beta$ of 0.50 and coefficients ranging from 0.14 to 0.88 for the perceived-usefulness - intention-to-use path. As for the effect of perceived ease of use on intention to use, there is a lack of consensus (for reviews, see Yousafzai, Foxall, \& Pallister, 2007 ; King and He, 2006). Some studies (e.g., Agarwal \& Prasad, 1997) have claimed that 
perceived ease of use has a direct effect on intention to use. For other studies this effect is indirect and mediated by perceived usefulness (e.g., Davis et al., 1989). Similarly, King and He (2006) calculated a mean $\beta$ of 0.19 in empirical studies for the perceivedease-of-use-intention-to-use path. This path is weaker than the perceived-usefulnessintention to use path, with many studies finding low path coefficients (ranging from -0.04 to 0.72$)$.

The TAM is today the most frequently used model of user acceptance (Hsiao \& Yang, 2011; Venkatesh, 2000). It is a parsimonious and widely applicable model. Numerous studies have extended it to fit different technologies (e.g., AmoakoGyampah, 2007; Choi \& Ji, 2015), different contexts (Brown, Massey, Montoya-Weiss, \& Burkman, 2002; Huang, Backman, Backman, \& Moore, 2013), and different users (Elias, Smith, \& Barney, 2012; Venkatesh \& Morris, 2000). The various extensions to the TAM that have been proposed (for a review of these, see Marangunić \& Granić, 2015) include factors from related models (e.g., subjective norm, perceived behavioral control), additional belief factors (e.g., triability, content richness), and external variables (e.g., demographic characteristics, computer self-efficacy). External variables can be antecedents or moderators of perceived usefulness and perceived ease of use. These extensions seek to increase the TAM's predictive power (e.g., Chow, Herold, Choo, \& Chan, 2012) by adding variables to fit it to specific technologies (e.g., an ERP ${ }^{1}$ for Amoako-Gyampah, 2007), contexts (e.g., Venkatesh, Thong, \& Xu, 2012) and users (e.g., Newbutt et al., 2016).

\footnotetext{
${ }^{1}$ ERP (Enterprise Resource Planning) are integrated systems that manage a company's inventory, logistics, orders, billing, shipping, sales, etc. (Amoako-Gyampah, 2007).
} 
The several studies that have used the TAM to examine an intention to use VR technologies have shown that the TAM may usefully be applied in the context of VR. These studies found that intention to use was predicted by perceived usefulness (Bertrand \& Bouchard, 2008; Chow et al., 2012; Fetscherin \& Lattemann, 2008; Tokel \& İsler, 2013) and perceived ease of use (Bertrand \& Bouchard, 2008; Chow et al., 2012; Fetscherin \& Lattemann, 2008; Tokel \& İsler, 2013). They also found a significant effect of perceived ease of use on perceived usefulness (Chow et al., 2012; Fetscherin \& Lattemann, 2008; Kim \& Forsythe, 2008; Tokel \& İsler, 2013). We therefore propose the following three hypotheses:

H1: Perceived ease of use has a positive effect on intention to use virtual reality technologies.

H2: Perceived usefulness has a positive effect on intention to use virtual reality technologies.

H3: Perceived ease of use has a positive effect on perceived usefulness.

\section{User experience $(\mathrm{UX})$}

As mentioned above, the TAM is based on two instrumental variables: perceived ease of use and perceived usefulness. In its original form the model does not consider hedonic qualities (e.g., enjoyment, esthetics, emotions). However, some studies suggest that hedonic qualities can explain the intention to use a technology. For instance, Venkatesh and Speier (1999) showed that users' positive and negative moods affect both intrinsic motivation and the intention to use a technology. More specifically, the authors showed that positive mood had a short-term impact on intrinsic motivation and intention to use, whereas negative mood had a long-term impact on them. The effects of 
positive mood were observed at the time of a training session with the technology but were no longer observed six weeks later. The effects of negative mood, however, were still apparent six weeks after the training session.

A number of authors have studied the effect of enjoyment on user acceptance. For instance, Davis, Bagozzi, and Warshaw (1992) showed that enjoyment has a positive impact on intention to use a technology in the workplace and that there is a positive interaction between enjoyment and perceived usefulness. Childers, Carr, Peck, and Carson (2001) proposed a model of user acceptance of online shopping that included both utilitarian and hedonic dimensions. Their results show that perceived enjoyment has an effect on attitude, on perceived usefulness and on perceived ease of use. Van der Heijden (2004) studied hedonic systems specifically and showed that perceived enjoyment and perceived ease of use are, for hedonic systems, stronger predictors of intention to use than perceived usefulness.

Virtual environments are perceived as hedonic technologies, as shown by studies that integrate both hedonic variables and utilitarian variables to explain user acceptance. Sun and Cheng (2009) showed that perceived playfulness has a positive effect on perceived usefulness, on perceived ease of use, and on user attitudes regarding a VR application based on a webcam. Similarly, Tokel and İsler (2013) found that perceived enjoyment has a positive effect on perceived usefulness, on perceived ease of use, and on the intention to use virtual worlds as a learning space. These studies suggest that hedonic variables are a determinant of technology acceptance (Diefenbach, Kolb, \& Hassenzahl, 2014), and for this reason we propose integrating user experience into the TAM.

User experience (UX) is defined as a “person's perceptions and responses resulting from the use and/or anticipated use of a product, system or service" 
(International Organization for Standardization [ISO], 2010). For Hassenzahl (2008), a good user experience is the consequence of fulfilling a user's goals (do-goals, such as finding information in a database or making a phone call) and of fulfilling different human needs (be-goals, such as the needs for autonomy, relatedness and stimulation). Hassenzahl consequently proposed a model of user experience featuring pragmatic attributes and hedonic attributes (Hassenzahl, 2003, 2008). Pragmatic attributes refer to "the product's perceived ability to support the achievement of 'do-goals"” (Hassenzahl, 2008, p. 2). Hedonic attributes refer to "the product's perceived ability to support the achievement of "be-goals"” (Hassenzahl, 2008, p. 2). Hedonic attributes can be subdivided into stimulation, identification and evocation (Hassenzahl, 2003). Stimulation refers to the individual's pursuit of novelty and challenge. Identification is the ability of a product to communicate identity. Evocation is the ability of a product to represent memories of past events or past relationships that are important to the user. These pragmatic and hedonic attributes determine (Hassenzahl, 2003) to what extent a product will be found attractive, its emotional consequences, and its behavioral consequences (including whether and how the product will be used).

Some authors have combined the TAM and UX to explain intention to use a technology. Van Schaik and Ling (2011) proposed an integrated experience-acceptance model. They showed that perceptions of the product's attributes (hedonic and pragmatic qualities) were a determinant of beliefs about the technology (perceived usefulness, perceived ease of use, and perceived enjoyment). Kauer, Theuerling, and Bruder (2013) proposed a balanced TAM, combining, on the one hand, perceived usefulness, perceived ease of use and perceived enjoyment from the technology acceptance model, and on the other hand identification and stimulation from Hassenzahl, Diefenbach, and Göritz's (2010) needs approach. They showed that prediction of intention to use is 
improved when hedonic qualities are included. In the light of these various studies we propose integrating UX variables into the TAM, and we make the following hypotheses:

H4a: Pragmatic quality has a positive effect on perceived ease of use.

H4b: Pragmatic quality has a positive effect on perceived usefulness.

H5a: Hedonic quality stimulation has a positive effect on perceived ease of use.

H5b: Hedonic quality stimulation has a positive effect on perceived usefulness.

\section{Cybersickness}

Exposure to a virtual environment can have negative side effects. Users can develop symptoms such as eyestrain, headache, pallor, sweating, a dry mouth, stomach discomfort, disorientation, vertigo, ataxia, nausea and vomiting (Cobb, Nichols, Ramsey, \& Wilson, 1999; LaViola, 2000). These symptoms resemble the symptoms of motion sickness, but in the absence of physical motion they bear different names (Rebenitsch \& Owen, 2016) such as cybersickness, simulator sickness, Virtual Induced Motion Sickness (VIMS), Virtual Reality Symptoms and Effects (VRISE), etc.

Kennedy and Lane (1993) developed the Simulator Sickness Questionnaire (SSQ) to evaluate symptoms following simulator exposure. Using a large body of data from users of flight simulators they identified three types of symptoms: nausea (e.g., stomach awareness), oculomotor (e.g., eyestrain) and disorientation (e.g., vertigo). SSQ is the questionnaire most often used in cybersickness studies (Rebenitsch \& Owen, 2016).

Cybersickness is a relatively common negative outcome of exposure to virtual environments. Symptoms differ according to the individual, the type of equipment and how it is used (Nichols \& Patel, 2002). Studies have suggested that between $60 \%$ 
(Regan, 1997) and 80\% (Cobb et al., 1999) of participants exposed to VR will experience an increase in symptoms of cybersickness. However, these symptoms are short-lived, as most participants recover in an hour, but some effects (such as disorientation) can linger for several hours (Rebenitsch \& Owen, 2016). Cybersickness may stop users from using a particular technology again (Biocca, 1992; Diels \& Howarth, 2013; Lin \& Parker, 2007). Therefore, we propose the following hypothesis:

H6: Cybersickness has a negative effect on intention to use virtual reality technologies.

\section{Presence}

Presence is a subjective sensation which allows users to interact with and feel connected to a world outside of themselves (Thornson, Goldiez, \& Le, 2009). Since most virtual environments seek to create this sensation, presence is an important dimension in assessments of VR (Kober \& Neuper, 2013). Large research efforts are being made in various disciplines (engineering, psychology, design, etc.) to gain a better understanding of presence and to develop technologies for enhancing it (Thornson, Goldiez, \& Le, 2009).

Several definitions of presence are to be found in the literature. The term presence grew out of the concept of telepresence, first coined by Minsky (1980), which describes the feeling of being physically transported to a remote workspace via teleoperating systems. Sheridan (1992) then distinguished between telepresence and virtual presence. He reserved the term virtual presence to mean the feeling of being physically present in a virtual environment, and this is the sense in which most authors today use the term presence.

One of the most common definitions of presence in a virtual environment describes it as the perceptual illusion of nonmediation (Lombard \& Ditton, 1997). This 
illusion occurs when the user fails to acknowledge the technology and interacts with the virtual environment just as they would act in the "real" world. This idea of nonmediation was adopted by the International Society for Presence Research (ISPR) founded in 2000. Under the ISPR definition, telepresence was shortened to presence. It denotes a sense of 'being there' in a virtual environment and is more broadly defined as an illusion of nonmediation in which users of any technology overlook or misconstrue the technology's role in their experience".

The concept of presence exists alongside other concepts such as immersion. For Witmer and Singer (1998), immersion is "a psychological state characterized by perceiving oneself to be enveloped by, included in, and interacting with an environment that provides a continuous stream of stimuli and experiences" (p. 227). They state that involvement and immersion are necessary to experience presence. Slater (1999) also distinguishes between immersion and presence, but disagrees with Witmer and Singer's formulation. For Slater, presence is subjective and defined as "a state of consciousness, the (psychological) sense of being in the virtual environment" (Slater \& Wilbur, 1997, p. 4), whereas immersion is objective and refers to the extent to which the technology is capable of creating an illusion of reality for the user.

Presence is seen as one of the most important features of VR, with practical relevance for the design and evaluation of virtual environments (Lee, 2004; Makransky, Lilleholt, \& Aaby, 2017). However, only a few studies have taken account of presence when investigating user acceptance of VR (e.g., Benoit et al., 2015; Fornells-Ambrojo et al., 2008; Skopp, Smolenski, Metzger-Abamukong, Rizzo, \& Reger, 2014). To our knowledge, the study by Shin, Biocca, \& Choo (2013) is the only study that has anything to say about the effect of presence with regard to user acceptance of virtual environments. They proposed a modified technology acceptance model with constructs 
from expectation-confirmation theory (ECT), and found that presence has a positive influence in user acceptance through the confirmation of expectations.

We therefore share the opinion that although presence is a distinctive characteristic of VR, the effect of presence on user acceptance has not been sufficiently studied (Mütterlein \& Hess, 2017). We propose the following hypothesis:

H7: Presence has a positive effect on intention to use virtual reality.

\section{Personal innovativeness}

Personal innovativeness is defined as "the willingness of an individual to try out any new information technology" (Agarwal \& Prasad, 1998, p. 206).

Some studies have found that personal innovativeness has a direct impact on user acceptance of technologies. Yi, Fiedler, \& Park (2006) compared two alternative models: a first model in which personal innovativeness is a moderator of the effects of innovation characteristics (usefulness, ease of use) on intention to use, and a second model in which personal innovativeness has a direct effect on innovation characteristics and on intention to use. Their results suggest that personal innovativeness has a direct impact on usefulness, ease of use and compatibility. Similarly, Kim \& Forsythe (2010) showed that personal innovativeness has a direct effect on perceived usefulness, perceived ease of use and perceived enjoyment in the context of a product virtualization technology. Fagan, Kilmon, \& Pandey (2012) also found that personal innovativeness directly affected the perceived usefulness of, perceived ease of use of, and intention to use a VR simulation designed to teach nursing students how to use a medical emergency crash cart. Given these studies showing a direct impact of personal innovativeness on user acceptance of technology, we propose the following hypotheses:

H8a: Personal innovativeness has a positive effect on perceived usefulness. 
H8b: Personal innovativeness has a positive effect on perceived ease of use.

H8c: Personal innovativeness has a positive effect of intention to use virtual reality.

\section{Research model}

Figure 1 summarizes our research model and illustrates the hypothesized relationships among the variables.

\section{Insert Fig.1}

Figure 1. The research model depicting the relationship between the variables investigated in the study

\section{Methodology}

\section{Participants and data collection}

The participants in this study were undergraduate students in psychology and graduate students in engineering. They were recruited on a voluntary basis through social networks, in class and in cafeterias.

Data was collected via questionnaires. We excluded from the data analysis responses with missing values $(n=9)$ and responses where the experimental conditions were not optimal due to bugs or interruptions during the test $(n=4)$. Overall, 89 participants (45 women and 44 men) completed the questionnaire in full. They were aged 18 to $29(M=21.4, S D=2.18)$. Most of the subjects $(59.6 \%)$ were students in engineering $(n=53)$. The rest of the sample $(40.4 \%)$ were students in psychology $(n=$ 36). Half of the participants $(n=45)$ had never used VR technologies before. Among the participants with experience of VR, most had previously used head-mounted displays (37\%). Eleven participants (12\%) had used a cave automatic virtual environment (CAVE). 
Participants were randomly assigned to a VR device: one group performed the task with a head-mounted display (HMD) and the other performed the task in a CAVE. Fifty-two participants (58.4\%) used the HMD and thirty-seven participants (41.6\%) used the CAVE. Twenty-eight participants (31.5\%) had previously used the technology that they were assigned to in the experiment.

\section{Apparatus}

The virtual environment used in this study was developed using Unity3D by the Heudiasyc Laboratory (Sorbonne universités, Université de technologie de Compiègne) for aeronautical training purposes (Carpentier \& Lourdeaux, 2013). The virtual environment represents an aircraft manufacturing workshop (Figure 2). Participants were asked to perform an assembly task that involved a series of short assembly operations in order to rivet two components. All the subjects, whether assigned to the HMD or the CAVE, performed the task using HTC Vive controllers.

\section{Insert Fig. 2}

Figure 2. Screenshot of the virtual environment

The CAVE used in this study consisted of three $3.4 \mathrm{~m} \times 2.5 \mathrm{~m}$ glass screens and a $7.0 \mathrm{~m}$ x $3.4 \mathrm{~m}$ reflective painted floor. Rendering was done by four stereoscopic 3D projectors with 1920x1200 pixel resolution coupled with two NVIDIA M6000 graphics cards in one PC. The tracking system consisted of 10 Optitrack infrared cameras that detected the position in space of the HTC Vive controllers, with constellations composed of reflective spheres.

The HMD used in this study was an HTC Vive providing separate displays for each eye with $1080 \times 1200$ resolution (2160x1200 in total), yielding a $100^{\circ}$ horizontal 
field of view with a refresh rate of $90 \mathrm{~Hz}$. It was connected to an HP ZBook $17 \mathrm{G} 3$ with an Intel Core i7 (Quad-Core 2.6 GHz / 3.5 GHz Turbo), 8 GB RAM and a NVIDIA Quadro M5000M graphic card.

\section{Measures}

All constructs apart from cybersickness were measured using a 7-point Likert scale ranging from 1 (strongly disagree) to 7 (strongly agree). All of the items used had been adapted from validated questionnaires, translated into French, and already used in French in previous research.

To measure personal innovativeness we used the 4 items of Agarwal \& Prasad (1998) (Février, 2011 [in French]). Perceived usefulness and perceived ease of use were measured using scales from Davis (1989) and translated into French (Mansour \& Bouslama, 2012). The perceived usefulness scale consisted of 4 items and the perceived ease of use scale 4 items. Intention to use scale consisted of 2 items developed by Fishbein and Ajzen (1975) and translated into French (Mansour \& Bouslama, 2012). Pragmatic quality and hedonic quality stimulation were measured using the two 7-item scales from AttakDiff 2 (Hassenzahl, Burmester, \& Koller, 2003), translated into French (Lallemand, Koenig, Gronier, \& Martin, 2015). Presence was measured using a French version (proposed by Cyberpsychology Lab of UQO, 2013a) of the 19 items in the Witmer and Singer (1998) Presence Questionnaire. Cybersickness was measured using the 16 items from the Simulator Sickness Questionnaire (Kennedy \& Lane, 1993), translated into French (Cyberpsychology Lab of UQO, 2013b). Symptoms of cybersickness were measured using a 4-point Likert scale $(0=$ not at all, $1=$ slightly, $2=$ moderately, $3=$ very). 


\section{Procedure}

On their arrival participants were given information about the research project and the objectives of the experiment. They were then asked for their written consent for participating in the study, and informed that they were free to stop participating at any time.

Participants began by completing questionnaires to provide data about their demographics, previous experience with VR, and cybersickness symptoms before immersion. They then performed the VR task. This consisted, first, of a training phase in which they had to follow written instructions to learn how to use the controllers and how to do the assembly operations and, second, of the assembly task itself. Finally, they filled out a second series of questionnaires on cybersickness symptoms, presence, user experience, and user acceptance. The experiment lasted approximately one hour, including filling out the questionnaires.

\section{Data analysis}

Partial least squares structural equation modeling (PLS-SEM) is a flexible method of structural equation modeling that can be applied in a wide range of situations (Hair, Hult, Ringle, \& Sarstedt, 2014) and whose requirements in relation to sample size (Haenlein \& Kaplan, 2004) and distribution (Chin, 1998) are less restrictive than other modeling approaches. For the present study we chose to use PLS-SEM because of our small sample size. We conducted the analysis with SmartPLS 3 (Ringle, Wende, \& Becker, 2015). As recommended, we did the data analysis in two stages (Hair, Hult, Ringle, \& Sarstedt, 2014). First, we assessed the internal consistency, the convergent validity and the discriminant validity of the measurement model. Second, given that the results of the first stage were satisfactory, we used the structural model to test our hypotheses. 


\section{Results}

\section{Measurement model}

Since presence and cybersickness have more than one dimension, we tested a hierarchical component model to ensure their validity and reliability. These secondorder constructs (presence and cybersickness) have a formative measurement, while the first-order constructs have a reflective measurement. A formative measurement model assumes that the indicators cause the construct, whereas a reflective measurement assumes that the measures represent the manifestations of an underlying construct (Hair et al., 2014). As we faced the two types of measurement models, we therefore used a reflective-formative model (Becker, Klein, \& Wetzels, 2012; Hair et al., 2014).

Presence was divided into five reflective first-order constructs, namely realism, ability to act, interface quality, ability to examine, and self-assessment of performance. These dimensions were based on a factor analysis performed on the French version of the Presence Questionnaire (Cyberpsychology Lab of UQO, 2013). Cybersickness was also made a formative second-order construct. It comprised two dimensions based on the French version of the Simulator Sickness Questionnaire, namely nausea and oculomotor (Bouchard, Robillard, \& Renaud, 2007).

In line with previous research we used a two-step approach when assessing our constructs (Becker et al., 2012; Duarte \& Amaro, 2018). The first step was to assess the quality of the first-order constructs using the quality criteria for reflective constructs (i.e., internal consistency, convergent validity and discriminant validity) (Hair et al., 2014). The second step was to use the scores of the latent variables as indicators for our second-order constructs (presence and cybersickness) and to assess the quality of these second-order constructs using the quality criteria for formative constructs (i.e., weights 
of the first-order constructs on the second-order constructs and their significance)

(Duarte \& Amaro, 2018; Hair et al., 2014; Henseler, Ringle, \& Sinkovics, 2009).

In the first step (that is to say, assessing the quality of the first-order constructs) we chose to use Composite Reliability (CR) rather than Cronbach's alpha for internal consistency. Cronbach's alpha is seen as a conservative measure of internal consistency reliability because it is sensitive to the number of items and also assumes that each item is equally reliable (Hair et al., 2014). In contrast, CR considers the different outer loadings of the items. It is recommended that CR values are above .70 (Hair, Ringle, \& Sarstedt, 2011). To assess the convergent validity of the constructs we used factor loading values and the average variance extracted (AVE). It is recommended that factor loading values are above 0.7 and AVE values above 0.5 (Hair et al., 2014). To examine the discriminant validity of the constructs we used the Fornell-Larcker criterion by comparing the AVE square root of each construct against correlations between the other latent variables (Fornell \& Larcker, 1981). The AVE square root for each factor should be larger than its correlation coefficients with other factors (Chin, 1998). Henseler, Ringle, and Sarstedt (2015) also proposed the heterotrait-monotrait ratio of correlations (HTMT), a new criterion for assessing discriminant validity. The HTMT should be significantly less than 1 .

To ensure convergent validity, the three items PQ1, HQS3, HQS6 were excluded from the model because of their low loadings (loading value $<.40$ ). To ensure discriminant validity, the item AE2 was also excluded because it loaded on two different subscales. The CR values were above the recommended threshold value of .70 for all the items, excepted Nausea (.46), Oculomotor (.39). The scale Ability to examine had a CR of .67, which can be considered acceptable (Bagozzi \& Yi, 1988). The AVE values were above the recommended value of 0.5 (Hair et al., 2014), other than for 
Nausea (.14), Oculomotor (.27), Ability to act (.49) and Realism (.42). Table 1 presents CR and AVE values for all the constructs.

To assess discriminant validity we used the Fornell-Larcker criterion and the HTMT values. With respect to the Fornell-Larcker criterion, all AVE values were also greater than correlations with other constructs, except for the correlation between Pragmatic quality and Perceived ease of use. However, the HTMT values were less than 1 for all the constructs, including Pragmatic quality and Perceived ease of use. Only two correlations between constructs of presence were greater than 1, namely the correlation between Self-assessment of performance and Ability to examine (1.17), and the correlation between Ability to examine and Ability to act (1.31). These results suggest an acceptable discriminant quality. Table 2 shows the AVE square root on the diagonal and the correlations among constructs and Table 3 shows the HTMT results. Overall, these results suggest some issues with psychometric qualities of the Presence questionnaire and the Simulator Sickness Questionnaire. However, we decided to retain the scales Nausea, Oculomotor, and Ability to act as they were contributing to the content validity of the two constructs Presence and Cybersickness. This choice and its limitations would be discussed in the Discussion section of this paper.

\section{Insert Table 1.}


Insert Table 2. 
The second step (that is to say, assessing the second-order constructs presence and cybersickness) involved using the scores of the latent variables as indicators. We assessed the quality of these second-order constructs using the quality criteria for formative constructs (Duarte \& Amaro, 2018; Hair et al., 2014; Henseler, Ringle, \& Sinkovics, 2009). We examined the weights of the first-order constructs on the secondorder constructs and their significance. The weights of the first-order constructs should either be significant and above the recommended value of .10 (Andreev, Heart, Maoz, \& Pliskin, 2009), or, where they are insignificant, the loadings of the indicators should be above 0.50 (Hair et al., 2014). We also tested for collinearity by checking that VIF values were less than 5 (Hair et al., 2014).

We found that weights of our first-order constructs were all above .10, with the exception of the indicator Ability to Act. For cybersickness, the $p$ values of the weights of Nausea and Oculomotor were significant $(p<.05)$. For presence, only Realism has a significant weight $(\mathrm{p}<.01)$. Given that some of the weights were insignificant, we calculated the loadings of the indicators, and found that all of them were above the recommended threshold value of 0.50, except for the Self-assessment of performance indicator, which we retained in order to ensure content validity. All the VIF values were lower than 5, indicating no collinearity issues (Hair et al., 2014). Table 4 presents the weights, their significance and the loadings of the first-order constructs.

Insert Table 4.

\section{Structural model}

We used bootstrapping to test the relationships hypothesized in our model. Path significance was tested using a bootstrapping technique for the 89 cases, with 5000 samples and no sign changes as recommended by Hair, Ringle, \& Sarstedt (2011). 
Table 4 lists all path coefficients and their significance. Our model can explain $47 \%$ of the variance in perceived ease of use, $31 \%$ of the variance in perceived usefulness, and $42 \%$ of the variance in intention to use. As a rule of thumb, $\mathrm{R}^{2}$ values can describe the level of predictive accuracy: values of 0.25 and less are weak, values between 0.25 and 0.75 are moderate and values exceeding 0.75 are strong (Hair et al., 2011; Henseler et al., 2009), meaning that our model has a moderate level of predictive accuracy for these three variables.

Perceived usefulness had a significant effect on intention to use VR, which supported H1. Perceived ease of use was not significantly correlated either with intention to use VR or with perceived usefulness, meaning that $\mathrm{H} 2$ and $\mathrm{H} 3$ were not supported. Pragmatic quality had a significant effect on perceived ease of use, but not on perceived usefulness, and so $\mathrm{H} 4 \mathrm{a}$ was supported but not $\mathrm{H} 4 \mathrm{~b}$. Hedonic qualitystimulation was significantly correlated with perceived usefulness, but not with perceived ease of use. H5a was therefore not supported, while H5b was. Cybersickness had a significant negative effect on intention to use VR, supporting H6. Presence was not significantly correlated with intention to use, and so H7 was not supported. Personal innovativeness had a significant effect on perceived usefulness but not on perceived ease of use and intention to use, supporting H8b but not H8a and H8c. The results are summarized in Table 4. Figure 3 shows the relationships in the research model, along with path coefficients and $p$ values.

\section{Insert Table 5.}

\section{Insert Fig. 3}

Figure 3. Model estimation results

Note. Bold lines show significant paths. Dotted lines show no significant paths.

$* p<.05 ; * * p<.01$ 


\section{Discussion and conclusion}

This study contributes to the user acceptance literature by combining variables from "traditional" models of user experience (i.e., pragmatic quality and hedonic quality stimulation) with user characteristics (i.e., personal innovativeness) and with variables specific to VR experience (i.e., presence and cybersickness).

In contrast to previous studies, in our study we did not find perceived ease of use to have a significant effect on intention to use VR. It has sometimes been suggested that although perceived ease of use has no direct effect on intention to use, it might nevertheless have an indirect effect mediated by perceived usefulness (Davis et al., 1992, 1989). In our study, we found no significant effect of perceived ease of use on user acceptance of VR, either directly on intention to use or indirectly via perceived usefulness. By implication, it suggests that the application we evaluated does not need to be easy to use in order to be considered useful and for users to intend to use it. However, most of the studies in virtual environment or in virtual reality do find a significant effect of perceived ease of use on intention and on perceived usefulness (e.g., Manis \& Choi, 2018; Tokel \& İsler, 2013; Yeh \& Lin, 2019). We believe that several reasons can explain this lack of significance of perceived ease of use in our study. First, it might be explained by the instability of the effect of perceived ease of use, a point raised in two meta-analyses of the results of the TAM (King \& He, 2006; Lee, Kozar, \& Larsen, 2003). Our small sample size might also explain the lack of significance of perceived ease of use on intention to use. Indeed, King and He (2006) indicated in their meta-analyses that, because of the instability of perceived ease of use, a sample size of 225 or more would be required to have a $80 \%$ chance of finding a significant perceived ease of use - intention to use path, whereas for the perceived usefulness - intention to use path a sample size of 28 or more would be required. 
Another explanation could be the importance of perceived usefulness, which has been shown by several studies to be a stronger predictor of intention to use than perceived ease of use (e.g., Davis, 1989; Davis et al., 1989). Perceived usefulness might be expected to be even more important for utilitarian technologies (Van der Heijden, 2004) such as that used in our study. However, the size of our sample cannot completely explain the lack of significance of the perceived ease of use-perceived usefulness path, as a sample size of 31 would give $80 \%$ chance to conclude significance (King \& $\mathrm{He}$, 2006). For Subramanian (1994), perceived ease of use has less or no impact on the technology acceptance, when technologies in studies are by nature relatively easy to use. It might explain the weak importance of perceived ease of use in our study as participants were asked to perform a task following instructions. The virtual environment used in this study also includes one task only and it was relatively short. In previous studies that found a significant effect of perceived ease of use in the acceptance of virtual reality and virtual environments, participants had to judge the ease of use of the technology according to several tasks to perform. For instance, in the study by Chow et al. (2012), participants used a virtual environment to perform a rapid sequence intubation. They had to visit different places (virtual classroom, dressing room, virtual ward) and to perform different tasks. In this study, the effects of perceived ease of use on perceived usefulness and on intention to use were significant.

On the other hand, we found a significant effect of perceived usefulness on intention to use VR, suggesting that users must consider VR to be useful to intend to use it. This finding is in line with previous works that have addressed the issue of user acceptance in the context of virtual environments (e.g., Bertrand \& Bouchard, 2008; Chow et al., 2012; Fetscherin \& Lattemann, 2008; Tokel \& İsler, 2013), and corresponds to what has also been found in studies on various technologies such as 
word processors, emailers, and telemedicine technologies (see Yousafzai et al., 2007, for a meta-analysis of the TAM).

In our study we were interested in the role of users' need for stimulation and included two variables from Hassenzahl's model of user experience (pragmatic quality, and hedonic quality-stimulation) in our model. Our results suggest that these variables affect perceived ease of use and perceived usefulness in different ways. Perceived ease of use was influenced by pragmatic quality, while the effect of hedonic qualitystimulation was insignificant. Perceived usefulness, on the other hand, was influenced by hedonic quality-stimulation but not by pragmatic quality. It would appear that for perceived ease of use users look to the achievement of their goals, whereas for perceived usefulness they look to the fulfillment of their needs. If users have a positive opinion of the attributes of a technology as they use it, they will consider the technology easy to use. On the other hand, they must judge a technology to be challenging before they will perceive it as useful. The influence of stimulation on perceived usefulness may depend on the nature of the application. In our study VR was used for training, and the fact that users needed to find the application challenging in order to consider it useful might be a feature of this VR application in particular.

Cybersickness has a significant negative effect on intention to use VR, the more severe the symptoms of cybersickness, the less willing users were to use VR. This finding is in line with different studies that found that cybersickness may stop users from using immersive technologies again (Biocca, 1992; Diels \& Howarth, 2013; Lin \& Parker, 2007).

The effect of presence on intention to use VR was found to be insignificant, but it must be remembered that our model investigated only a direct effect of presence on intention to use. It is unclear precisely how presence might potentially affect user 
acceptance of VR. It might influence users' perceptions (perceived usefulness and perceived ease of use), or it might mediate the effect of these variables on the intention to use VR. Presence might also have an effect on variables not included in this model, such as perceived enjoyment or flow (Weibel, Wissmath, Habegger, Steiner, \& Groner, 2008).

Users' characteristics have an impact on how they perceive VR. Personal innovativeness affects perceived usefulness: users who are attracted to new technologies are more likely to judge VR as useful. However, we found the effect of personal innovativeness on perceived ease of use and intention to use to be insignificant, implying that users' perceptions of the ease of use of VR does not depend on their interest in new technologies, but that instead they are influenced by pragmatic qualities. Users attracted to new technologies do not necessarily intend to use VR. The effect of personal innovativeness on intention to use is indirect: users interested in new technologies are more likely to find it useful, and it is perceived usefulness that is a predictor of intention to use VR.

The model we propose also includes a number of variables, some of whose effects need to be further investigated. For instance, the roles played by presence and perceived ease of use need to be more clearly understood. Other studies on user acceptance of technologies have shown the impact of variables, such as perceived enjoyment, involvement, and previous experience, that might be included in future studies.

Although our findings provide meaningful implications for user acceptance of VR, we have identified limitations that need to be addressed in future research. First, as we mentioned it in the Method section, we highlight several psychometric issues with the scales we used to evaluate Presence and Cybersickness. Some subscales had 
relatively low AVE and some had low CR values. Also, some first-order constructs of presence had insignificant weights. These scales could be improved in future studies by exchanging several items and by testing the new-built instruments with large samples. We believe the psychometric issues we have encountered with the scales we used can be explained by several reasons. First, the structure of the questionnaires differs between the French and original versions. While the Simulator Sickness Questionnaire includes three factors - Nausea, Oculomotor and Disorientation - its translation includes only two - Nausea and Oculomotor. Similarly, the French version of the Presence Questionnaire includes five factors, while Witmer (2005) found that a 4-factor model provides the best fit for the data obtained with the original version. We believe that these structural differences need to be studied more carefully and that they can partly explain the issues we have encountered with these questionnaires. Indeed, only few studies have tested the structure of these questionnaires and with restricted sample sizes. Second, as these two measurements had several dimensions, we decided to use a hierarchical component model. Future studies should evaluate the effects of these variables using unidimensional scales, for instance the scale of presence of Slater, Usoh, \& Steed (1994). Although, the Simulator Sickness Questionnaire is still one the most widely used today to measure cybersickness, researchers recommend questionnaires specifically adapted to virtual reality (Stone, 2017); some have been recently proposed in the literature (Kim, Park, Choi, \& Choe, 2018).

Another limitation of our study is the sample size. The recruitment of participants was limited for practical reasons (limited access to the CAVE, participants having difficulties traveling to the research site). Because of the small sample size we chose to use PLS. With a larger sample size, structural equation modeling would make it possible to compare competing models (West, Taylor, \& Wu, 2012) and to examine 
the relative advantages to be gained by including UX, presence, cybersickness and personal innovativeness in the TAM. Moreover, as mentioned earlier, with a larger sample size - of 225 participants of more - we could better understand the influence of perceived ease of use in user acceptance of virtual reality. Its effect on intention to use was insignificant in our study but this path requires a large sample size. Since the task used in this study was relatively short and simple, future studies should also evaluate more complex tasks that might require to be easy to use for participants to find it useful and to intend to use it.

Moreover, this study investigates user acceptance of a specific virtual training environment, and our subjects were students with little or no familiarity with the target domain. Future research should integrate real end-users (i.e., actual aeronautical trainees).

\section{Acknowledgements}

This study is part of the LEON project (acceptability of emerging technologies in aeronautics) funded by the Picardy regional authority and by the European Regional Development Fund (FEDER). The task used in this study was part of the NIKITA project (ANR-10-CORD-0014) and the virtual environment used was developed by EMISSIVE (http://www.emissive.fr/fr/). The CAVE used in this study (called Translife) is hosted by Heudiasyc (CNRS UMR 7253) and funded by the Picardy regional authority and by the European Regional Development Fund (FEDER).

We thank Samba Drame for developing the virtual environment and for his help with the experiments in the CAVE. We also thank Savinien Colinet, Laura Liepchitz, Julie Berteaux, and Yuchen Qiu for their precious help with the experiments. We are also grateful to Geoffrey Blondelle for his precious comments on an earlier draft of this 
paper and to Fabien Cerrotti who helped us during the revising process.

We also thank the anonymous reviewers for their valuable comments and suggestions.

\section{Declaration of interest statement}

The authors declare that they have no conflict of interest.

\section{References}

Agarwal, R., \& Prasad, J. (1997). The role of innovation characteristics and perceived voluntariness in the acceptance of information technologies. Decision Sciences, 28(3), 557-582. https://doi.org/10.1111/j.1540-5915.1997.tb01322.x

Agarwal, R., \& Prasad, J. (1998). A conceptual and operational definition of personal innovativeness in the domain of information technology. Information Systems Research, 9(2), 204-215. https://doi.org/10.1287/isre.9.2.204

Ajzen, I. (1991). The theory of planned behavior. Orgnizational Behavior and Human Decision Processes, 50, 179-211. https://doi.org/10.1016/0749-5978(91)90020-T

Amoako-Gyampah, K. (2007). Perceived usefulness, user involvement and behavioral intention: an empirical study of ERP implementation. Computers in Human Behavior, 23(3), 1232-1248. https://doi.org/10.1016/j.chb.2004.12.002

Andreev, P., Heart, T., Maoz, H., \& Pliskin, N. (2009). Validating formative partial least squares (PLS) models: Methodological review and empirical illustration. International Conference on Information Systems, (November 2015), 1-17.

Bagozzi, R., \& Yi, Y. (1988). On the evaluation of structural equation models. Journal of the Academy of Marketing Science, 16(1), 74-94.

Becker, J. M., Klein, K., \& Wetzels, M. (2012). Hierarchical latent variable models in PLS-SEM: Guidelines for using reflective-formative type models. Long Range Planning, 45(5-6), 359-394. https://doi.org/10.1016/j.lrp.2012.10.001

Benoit, M., Guerchouche, R., Petit, P. D., Chapoulie, E., Manera, V., Chaurasia, G., ... Robert, P. (2015). Is it possible to use highly realistic virtual reality in the elderly? A feasibility study with image-based rendering. Neuropsychiatric Disease and 
Treatment, 11, 557-563. https://doi.org/10.2147/NDT.S73179

Bertrand, M., \& Bouchard, S. (2008). Applying the technology acceptance model to vr with people who are favorable to its use. Journal of Cyber Therapy and Rehabilitation, 1(2), 200-210.

Biocca, F. (1992). Will simulation sickness slow down the diffusion of virtual environment technology? Presence: Teleoperators and Virtual Environments, 1(3), 334-343. https://doi.org/10.1162/pres.1992.1.3.334

Bouchard, S., Robillard, G., \& Renaud, P. (2007). Revising the factor structure of the simulator sickness quesionnaire. Annual Review of CyberTherapy and Telemedicine, 5, 117-122.

Brown, S. A., Massey, A. P., Montoya-Weiss, M. M., \& Burkman, J. R. (2002). Do I really have to? User acceptance of mandated technology. European Journal of Information Systems, 11(4), 283-295.

https://doi.org/10.1057/palgrave.ejis.3000438

Carpentier, K., \& Lourdeaux, D. (2013, February). Generation of learning situations according to the learner's profile within a virtual environment. In International Conference on Agents and Artificial Intelligence (pp. 245-260). Springer, Berlin, Heidelberg.

Childers, T. L., Carr, C. L., Peck, J., \& Carson, S. (2001). Hedonic and utilitarian motivations for online retail shopping behavior. Journal of Retailing, 77(4), 511535. https://doi.org/10.1016/S0022-4359(01)00056-2

Chin, W. W. (1998). The Partial Least Squares approach to Structural Equation Modeling. In G. A. Marcoulides (Ed.), Modern methods for business research (pp. 295-358). Mahwah, NJ: Lawrence Erlbaum.

Choi, J. K., \& Ji, Y. G. (2015). Investigating the importance of trust on adopting an autonomous vehicle. International Journal of Human-Computer Interaction, 31(10), 692-702. https://doi.org/10.1080/10447318.2015.1070549

Chow, M., Herold, D. K., Choo, T. M., \& Chan, K. (2012). Extending the technology acceptance model to explore the intention to use Second Life for enhancing healthcare education. Computers and Education, 59(4), 1136-1144. https://doi.org/10.1016/j.compedu.2012.05.011 
Cobb, S. V. G., Nichols, S., Ramsey, A., \& Wilson, J. R. (1999). Virtual RealityInduced Symptoms and Effects (VRISE). Presence: Teleoperators and Virtual Environments, 8(2), 169-186. https://doi.org/10.1162/105474699566152

Cyberpsychology Lab of UQO. (2013a). Questionnaire sur l'état de présence

[Questionnaire]. Retrieved from

http://w3.uqo.ca/cyberpsy/docs/qaires/pres/QEP_vf.pdf

Cyberpsychology Lab of UQO. (2013b). Questionnaire sur les cybermalaises

[Questionnaire]. Retrieved from

http://w3.uqo.ca/cyberpsy/docs/qaires/ssq/SSQ_vf.pdf

Davis, F. D. (1989). Perceived usefulness, perceived ease of use, and user acceptance of information technology. MIS Quarterly, 13(3), 319-340.

Davis, F. D., Bagozzi, R. P., \& Warshaw, P. R. (1992). Extrinsic and intrinsic motivation to use computers in the workplace. Journal of Applied Social Psychology, 22(14), 1111-1132. https://doi.org/10.1111/j.15591816.1992.tb00945.x

Davis, F. D., Bagozzi, R., \& Warshaw, P. (1989). User acceptance of computer technology: a comparison of two theoretical models. Mangagement Science, 35(8), 982-1002. https://doi.org/10.1287/mnsc.35.8.982

Diefenbach, S., Kolb, N., \& Hassenzahl, M. (2014). The 'Hedonic' in human-computer interaction - History, contributions, and future research directions. Proceedings of the Conference on Designing Interactive Systems, (June), 305-314. https://doi.org/10.1145/2598510.2598549

Diels, C., \& Howarth, P. a. (2013). Frequency characteristics of visually induced motion sickness. Human Factors, 55(3), 595-604. https://doi.org/10.1177/0018720812469046

Duarte, P., \& Amaro, S. (2018). Methods for modelling reflective-formative second order constructs in PLS. Journal of Hospitality and Tourism Technology, JHTT09-2017-0092. https://doi.org/10.1108/JHTT-09-2017-0092

Elias, S. M., Smith, W. L., \& Barney, C. E. (2012). Age as a moderator of attitude towards technology in the workplace: Work motivation and overall job satisfaction. Behaviour \& Information Technology, 31(5), 453-467. 
https://doi.org/10.1080/0144929X.2010.513419

Fagan, M., Kilmon, C., \& Pandey, V. (2012). Exploring the adoption of a virtual reality simulation. Campus-Wide Information Systems, 29(2), 117-127. https://doi.org/10.1108/10650741211212368

Fetscherin, M., \& Lattemann, C. (2008). User acceptance of virtual worlds, 9(3), 231242.

Février, F. (2011). Vers un modèle intégrateur "expérience-acceptation” : rôle des affects et de caractéristiques personnelles et contextuelles dans la détermination d'usage d'un environnement numérique de travail (Doctoral thesis, Université de Rennes 2, Rennes, France). Retrieved from https://tel.archives-ouvertes.fr/tel00608335/document

Fishbein, M., \& Ajzen, I. (1975). Belief, attitude, intention and behavior: An introduction to theory and research. Reading, MA, Etats-Unis: Addison-Wesley.

Fornell, C., \& Larcker, D. F. (1981). Evaluating structural equation models with unobservable variables and measurement error. Journal of Marketing Research, 18(1), 39-50. Retrieved from http://www.jstor.org/stable/3151312

Fornells-Ambrojo, M., Barker, C., Swapp, D., Slater, M., Antley, A., \& Freeman, D. (2008). Virtual reality and persecutory delusions: Safety and feasibility. Schizophrenia Research, 104(1-3), 228-236. https://doi.org/10.1016/j.schres.2008.05.013

Freeman, D., Bradley, J., Antley, A., Bourke, E., DeWeever, N., Evans, N., ... Clark, D. M. (2016). Virtual reality in the treatment of persecutory delusions: randomised controlled experimental study testing how to reduce delusional conviction. The British Journal of Psychiatry, 209(1), 62-67. https://doi.org/10.1192/bjp.bp.115.176438

Gavish, N., Gutiérrez, T., Webel, S., Rodríguez, J., Peveri, M., Bockholt, U., \& Tecchia, F. (2015). Evaluating virtual reality and augmented reality training for industrial maintenance and assembly tasks. Interactive Learning Environments, 23(6), 778-798. https://doi.org/10.1080/10494820.2013.815221

Haenlein, M., \& Kaplan, A. M. (2004). A beginner's guide to partial least squares analysis. Understanding Statistics, 3(4), 283-297. 
https://doi.org/10.1207/s15328031us0304_4

Hair, J. F., Hult, G. T. M., Ringle, C., \& Sarstedt, M. (2014). A primer on Partial Least Squares Structural Equation Modeling (PLS-SEM). Thousand Oaks, CA: SAGE.

Hair, J. F., Ringle, C. M., \& Sarstedt, M. (2011). PLS-SEM: Indeed a silver bullet. The Journal of Marketing Theory and Practice, 19(2), 139-152. https://doi.org/10.2753/MTP1069-6679190202

Hassenzahl, M. (2003). The thing and I: Understanding the relationship between user and product. In M. A. Blythe, K. Overbeeke, A. F. Monk, \& P. C. Wright (Eds.), Funology: From Usability to Enjoyment (Vol. 3, pp. 31-42). Dordrecht: Springer Netherlands. https://doi.org/10.1007/1-4020-2967-5_4

Hassenzahl, M. (2008). User experience (UX): Towards an experiential perspective on product quality. In Proceedings of the 20th International Conference of the Association Francophone d'Interaction Homme-Machine on - IHM '08 (p. 11). New York, New York, USA: ACM Press. https://doi.org/10.1145/1512714.1512717

Hassenzahl, M., Burmester, M., \& Koller, F. (2003). AttrakDiff: Ein fragebogen zur messung wahrgenommener hedonischer und pragmatischer qualität. In G. Szwillus \& J. Ziegler (Eds.), Mensch \& Computer 2003: Interaktion in Bewegung (pp. 187196). Wiesbaden: Vieweg+Teubner Verlag. https://doi.org/10.1007/978-3-32280058-9_19

Hassenzahl, M., Diefenbach, S., \& Göritz, A. (2010). Needs, affect, and interactive products - Facets of user experience. Interacting with Computers, 22(5), 353-362. https://doi.org/10.1016/j.intcom.2010.04.002

Henseler, J., Ringle, C. M., \& Sarstedt, M. (2015). A new criterion for assessing discriminant validity in variance-based structural equation modeling. Journal of the Academy of Marketing Science, 43(1), 115-135. https://doi.org/10.1007/s11747-014-0403-8

Henseler, J., Ringle, C. M., \& Sinkovics, R. R. (2009). The use of partial least squares path modeling in international marketing. Advances in International Marketing, 20(2009), 277-319. https://doi.org/10.1108/S1474-7979(2009)0000020014

Hornbæk, K., \& Hertzum, M. (2017). Technology acceptance and user experience. 
ACM Transactions on Computer-Human Interaction, 24(5), 1-30.

https://doi.org/10.1145/3127358

Hsiao, C. H., \& Yang, C. (2011). The intellectual development of the technology acceptance model: A co-citation analysis. International Journal of Information Management, 31(2), 128-136. https://doi.org/10.1016/j.ijinfomgt.2010.07.003

Hsu, S. Y., Fang, T. Y., Yeh, S. C., Su, M. C., Wang, P. C., \& Wang, V. Y. (2017). Three-dimensional, virtual reality vestibular rehabilitation for chronic imbalance problem caused by Ménière's disease: a pilot study*. Disability and Rehabilitation, 39(16), 1601-1606. https://doi.org/10.1080/09638288.2016.1203027

Huang, Y.-C., Backman, S. J., Backman, K. F., \& Moore, D. (2013). Exploring user acceptance of 3D virtual worlds in travel and tourism marketing. Tourism Management, 36, 490-501. https://doi.org/10.1016/j.tourman.2012.09.009

International Organization for Standardization. (2010). Ergonomics of human-system interaction - Part 210: Human-centred design for interactive systems (ISO 9241-210:2010). Retrieved from https://www.iso.org/standard/52075.html

International Society for Presence Research. (2000). The concept of presence: explication statement. Retrieved August 13, 2018, from https://ispr.info

Kauer, M., Theuerling, H., \& Bruder, R. (2013). The importance of identification for the acceptance of consumer electronics on the example of the Wii. Behaviour and Information Technology, 32(4), 344-358. https://doi.org/10.1080/0144929X.2012.724085

Kennedy, R., \& Lane, N. (1993). Simulator sickness questionnaire: An enhanced method for quantifying simulator sickness. The International Journal of Aviation Psychology, 3(3), 203-220.

Kim, H. K., Park, J., Choi, Y., \& Choe, M. (2018). Virtual reality sickness questionnaire (VRSQ): Motion sickness measurement index in a virtual reality environment. Applied Ergonomics, 69(December 2017), 66-73. https://doi.org/10.1016/j.apergo.2017.12.016

Kim, J., \& Forsythe, S. (2008). Adoption of Virtual Try-on technology for online apparel shopping. Journal of Interactive Marketing, 22(2), 45-59. https://doi.org/10.1002/dir.20113 
Kim, J., \& Forsythe, S. (2010). Factors affecting adoption of product virtualization technology for online consumer electronics shopping. International Journal of Retail \& Distribution Management, 38(3), 190-204. https://doi.org/10.1108/09590551011027122

King, W. R., \& He, J. (2006). A meta-analysis of the technology acceptance model. Information and Management, 43(6), 740-755. https://doi.org/10.1016/j.im.2006.05.003

Kober, S. E., \& Neuper, C. (2013). Personality and presence in virtual reality: Does their relationship depend on the used presence measure? International Journal of Human-Computer Interaction, 29(1), 13-25. https://doi.org/10.1080/10447318.2012.668131

Lallemand, C., Koenig, V., Gronier, G., \& Martin, R. (2015). Création et validation d'une version française du questionnaire AttrakDiff pour l'évaluation de l'expérience utilisateur des systèmes interactifs. Revue Européenne de Psychologie Appliquée/European Review of Applied Psychology, 65(5), 239-252. https://doi.org/10.1016/j.erap.2015.08.002

Lamb, R., Antonenko, P., Etopio, E., \& Seccia, A. (2018). Comparison of virtual reality and hands on activities in science education via functional near infrared spectroscopy. Computers and Education, 124(May), 14-26. https://doi.org/10.1016/j.compedu.2018.05.014

LaViola, J. J. (2000). A discussion of cybersickness in virtual environments. ACM SIGCHI Bulletin, 32(1), 47-56. https://doi.org/10.1145/333329.333344

Lee, K. M. (2004). Presence, Explicated. Communication Theory, 14(1), $27-50$. https://doi.org/10.1093/ct/14.1.27

Lee, Y., Kozar, K. A., \& Larsen, K. R. T. (2003). The Technology Acceptance Model: Past, present, and future. Communications of the Association for Information Systems, 12(1), 752-780. Retrieved from http://infosys.coba.usf.edu/bs/Lee03TAMcritique.pdf

Lessiter, J., Freeman, J., Keogh, E., \& Davidoff, J. (2001). A cross-media presence questionnaire: The ITC-Sense of presence inventory. Presence: Teleoperators and Virtual Environments, 10(3), 282-297. 
https://doi.org/10.1162/105474601300343612

Lin, Z., \& Filieri, R. (2015). Airline passengers' continuance intention towards online check-in services: The role of personal innovativeness and subjective knowledge. Transportation Research Part E: Logistics and Transportation Review, 81, 158168. https://doi.org/10.1016/j.tre.2015.07.001

Lin, J. J. W., \& Parker, D. E. (2007). User experience modeling and enhancement for virtual environments that employ wide-field displays. In Digital Human Modeling (pp. 423-433). Berlin, Heidelberg: Springer Berlin Heidelberg. https://doi.org/10.1007/978-3-540-73321-8_49

Lombard, M., \& Ditton, T. (1997). At the heart of it all: The concept of presence. Journal of Computer-Mediated Communication, 3(2). https://doi.org/10.1111/j.1083-6101.1997.tb00072.x

Makransky, G., Lilleholt, L., \& Aaby, A. (2017). Development and validation of the Multimodal Presence Scale for virtual reality environments: A confirmatory factor analysis and item response theory approach. Computers in Human Behavior, 72, 276-285. https://doi.org/10.1016/j.chb.2017.02.066

Manis, K. T., \& Choi, D. (2019). The virtual reality hardware acceptance model (VRHAM): Extending and individuating the technology acceptance model (TAM) for virtual reality hardware. Journal of Business Research, 100, 503-513. https://doi.org/10.1016/j.jbusres.2018.10.021

Mansour, K. Ben, \& Bouslama, N. (2012). Analyse de l'intention d'usage de la banque par internet : une extension du modèle d'acceptation de la technologie. In Congrès international de l'Association Française de Marketing. Brest, France. Retrieved from 20120603150143_S13_1_Ben_Mansour_et_Bouslama.pdf

Marangunić, N., \& Granić, A. (2015). Technology acceptance model: a literature review from 1986 to 2013. Universal Access in the Information Society, 14(1), 81-95. https://doi.org/10.1007/s10209-014-0348-1

Merchant, Z., Goetz, E. T., Keeney-Kennicutt, W., Kwok, O., Cifuentes, L., \& Davis, T. J. (2012). The learner characteristics, features of desktop 3D virtual reality environments, and college chemistry instruction: A structural equation modeling analysis. Computers \& Education, 59(2), 551-568. 
https://doi.org/10.1016/j.compedu.2012.02.004

Minsky, M. (1980). Telepresence. Omni, 2, 45-51.

Muhanna, M. A. (2015). Virtual reality and the CAVE: Taxonomy, interaction challenges and research directions. Journal of King Saud University - Computer and Information Sciences, 27(3), 344-361. https://doi.org/10.1016/j.jksuci.2014.03.023

Mütterlein, J., \& Hess, T. (2017). Immersion, presence, interactivity: Towards a joint understanding of factors influencing virtual reality acceptance and use. $23^{\text {rd }}$ Americas Conference on Information Systems (AMCIS), (August), 1-10.

Newbutt, N., Sung, C., Kuo, H.-J., Leahy, M. J., Lin, C.-C., \& Tong, B. (2016). Brief report: A Pilot study of the use of a virtual reality headset in autism populations. Journal of Autism and Developmental Disorders, 46(9), 3166-3176. https://doi.org/10.1007/s10803-016-2830-5

Nichols, S., \& Patel, H. (2002). Health and safety implications of virtual reality: A review of empirical evidence. Applied Ergonomics, 33(3), 251-271. https://doi.org/10.1016/S0003-6870(02)00020-0

Ordaz, N., Romero, D., Gorecky, D., \& Siller, H. R. (2015). Serious games and virtual simulator for automotive manufacturing education \& training. Procedia Computer Science, 75(Vare), 267-274. https://doi.org/10.1016/j.procs.2015.12.247

Rebenitsch, L., \& Owen, C. (2016). Review on cybersickness in applications and visual displays. Virtual Reality, 20(2), 101-125. https://doi.org/10.1007/s10055-0160285-9

Regan, C. (1997). Some effects of using virtual reality technology: Data and suggestions. In R. J. Seidel \& P. R. Chatelier (Eds.), Virtual Reality, Training's Future? (pp. 77-83). Boston, MA: Springer US.

Ringle, C., Wende, S., \& Becker, J. M. (2015). SmartPLS 3 [Computer software]. Retrieved from http://www.smartpls.com/

Serenko, A. (2008). A model of user adoption of interface agents for email notification. Interacting with Computers, 20(4-5), 461-472. https://doi.org/10.1016/j.intcom.2008.04.004 
Sharp, J. H. (2007). Development, extension, and application: A review of the Technology Acceptance Model. Information Systems Education Journal, 5(9), 111. Retrieved from http://www.isedj.org/5/9/ISEDJ.5(9).Sharp.pdf

Sheridan, T. B. (1992). Musings on telepresence and virtual presence. Presence: Teleoperators and Virtual Environments, 1(1), 120-126. https://doi.org/10.1162/pres.1992.1.1.120

Shin, D.-H., Biocca, F., \& Choo, H. (2013). Exploring the user experience of threedimensional virtual learning environments. Behaviour \& Information Technology, 32(2), 203-214. https://doi.org/10.1080/0144929X.2011.606334

Skopp, N. A., Smolenski, D. J., Metzger-Abamukong, M. J., Rizzo, A. A., \& Reger, G. M. (2014). A pilot study of the virtusphere as a virtual reality enhancement. International Journal of Human-Computer Interaction, 30(1), 24-31. https://doi.org/10.1080/10447318.2013.796441

Slater, M. (1999). Measuring presence: A response to the Witmer and Singer presence questionnaire. Presence: Teleoperators and Virtual Environments, 8(5), 560-565. https://doi.org/10.1162/105474699566477

Slater, M., Usoh, M., \& Steed, A. (1994). Depth of presence in virtual environments. Presence: Teleoperators and Virtual Environments, 3(2), 130-144. https://doi.org/10.1162/pres.1994.3.2.130

Slater, M., \& Wilbur, S. (1997). A Framework for Immersive Virtual Environments (FIVE): Speculations on the role of presence in virtual environments. Presence: Teleoperators and Virtual Environments, 6(6), 603-616. https://doi.org/10.1007/s10750-008-9541-7

Stone, W. B. (2017). Psychometric evaluation of the Simulator Sickness Questionnaire as a measure of cybersickness (Doctoral Dissertation). Available from Iowa State University Graduate Theses and Dissertations (No. 15429). Retrieved from https://lib.dr.iastate.edu/etd/15429

Subramanian, G. H. (2007). A Replication of Perceived Usefulness and Perceived Ease of Use Measurement. Decision Sciences, 25(5-6), 863-874. https://doi.org/10.1111/j.1540-5915.1994.tb01873.x

Sun, H. M., \& Cheng, W. L. (2009). The input-interface of Webcam applied in 3D 
virtual reality systems. Computers and Education, 53(4), 1231-1240.

https://doi.org/10.1016/j.compedu.2009.06.006

Sun, S., Sonka, M., \& Beichel, R. R. (2013). Lung segmentation refinement based on optimal surface finding utilizing a hybrid desktop/virtual reality user interface. Computerized Medical Imaging and Graphics, 37(1), 15-27. https://doi.org/10.1016/j.compmedimag.2013.01.003

Thornson, C. A., Goldiez, B. F., \& Le, H. (2009). Predicting presence: Constructing the tendency toward presence inventory. International Journal of Human Computer Studies, 67(1), 62-78. https://doi.org/10.1016/j.ijhcs.2008.08.006

Tokel, S. T., \& İsler, V. (2013). Acceptance of virtual worlds as learning space. Innovations in Education and Teaching International, 3297(January 2014), 1-11. https://doi.org/10.1080/14703297.2013.820139

Van der Heijden, H. (2004). User acceptance of hedonic information systems. MIS Quarterly, 28(4), 695-704.

Van Schaik, P., \& Ling, J. (2011). An integrated model of interaction experience for information retrieval in a Web-based encyclopaedia. Interacting with Computers, 23(1), 18-32. https://doi.org/10.1016/j.intcom.2010.07.002

Venkatesh, \& Speier. (1999). Computer technology training in the workplace: A longitudinal investigation of the effect of mood. Organizational Behavior and Human Decision Processes, 79(1), 1-28. https://doi.org/10.1006/obhd.1999.2837

Venkatesh, V. (2000). Determinants of perceived ease of use: Integrating control, intrinsic motivation, and emotion into the Technology Acceptance Model. Information Systems Research, 11(4), 342-365. https://doi.org/10.1287/isre.11.4.342.11872

Venkatesh, V., \& Morris, M. G. (2000). Why don't men ever stop to ask for directions? Gender, social influence, and their role in technology acceptance and usage behavior. MIS Quarterly, 24(1), 115. https://doi.org/10.2307/3250981

Venkatesh, V., Thong, J., \& Xu, X. (2012). Consumer acceptance and use of information technology: extending the unified theory of acceptance and use of technology. MIS Quarterly, 36(1), 157-178.

Weibel, D., Wissmath, B., Habegger, S., Steiner, Y., \& Groner, R. (2008). Playing 
online games against computer- vs. human-controlled opponents: Effects on presence, flow, and enjoyment. Computers in Human Behavior, 24(5), 2274-2291. https://doi.org/10.1016/j.chb.2007.11.002

West, S. G., Taylor, A. B., \& Wu, W. (2012). Model fit and model selection in structural equation modeling. Handbook of Structural Equation Modeling, 209231. https://doi.org/10.1016/j.surfcoat.2015.05.023

Witmer, B. G., \& Singer, M. J. (1998). Measuring presence in virtual environments: A presence questionnaire. Presence, 7(3), 225-240. https://doi.org/10.1162/105474698565686

Yeh, S.-C., \& Lin, P.-H. (2019). How Motion-Control Influences a VR-Supported Technology for Mental Rotation Learning: From the Perspectives of Playfulness, Gender Difference and Technology Acceptance Model. International Journal of Human-Computer Interaction, 1-11. https://doi.org/10.1080/10447318.2019.1571784

Yi, M. Y., Fiedler, K. D., \& Park, J. S. (2006). Understanding the role of individual innovativeness in the acceptance of it-based innovations: Comparative analyses of models and measures. Decision Sciences, 37(3), 393-426. https://doi.org/10.1111/j.1540-5414.2006.00132.x

Yoon, J., Lee, S., \& Park, T. (2018). JediFlight : Design and evaluation of wing-based flying experience in virtual reality. In Proceedings of the 2018 Annual Symposium on Computer-Human Interaction in Play Companion Extended Abstracts - CHI PLAY'18 Extended Abstracts (pp. 309-320). New York, New York, USA: ACM Press. https://doi.org/10.1145/3270316.3273043

Yousafzai, S. Y., Foxall, G. R., \& Pallister, J. G. (2007). Technology acceptance: a meta-analysis of the TAM: Part 1. Journal of Modelling in Management, 2(3), 251-280. https://doi.org/10.1108/17465660710834453 
TABLE 1

Psychometric properties of measurement model

\begin{tabular}{|c|c|c|c|c|c|}
\hline Constructs & Items & $M$ & $S D$ & AVE & CR \\
\hline \multirow[t]{4}{*}{ Perceived ease of use (PEOU) } & PEOU1 & 5.85 & 1.32 & .78 & .93 \\
\hline & PEOU2 & 5.57 & 1.23 & & \\
\hline & PEOU3 & 5.87 & 1.30 & & \\
\hline & PEOU4 & 5.83 & 1.24 & & \\
\hline \multirow[t]{4}{*}{ Perceived Usefulness (PU) } & PU1 & 5.11 & 1.49 & .66 & .88 \\
\hline & PU2 & 4.76 & 1.45 & & \\
\hline & PU3 & 4.79 & 1.51 & & \\
\hline & PU4 & 5.67 & 1.41 & & \\
\hline \multirow[t]{2}{*}{ Intention to use (IU) } & IU1 & 6.17 & 1.17 & .88 & .94 \\
\hline & IU2 & 6.37 & 0.98 & & \\
\hline \multirow[t]{6}{*}{ Pragmatic Quality (PQ) } & PQ2 & 5.45 & 1.33 & & \\
\hline & PQ3 & 5.46 & 1.18 & & \\
\hline & PQ4 & 5.27 & 1.24 & & \\
\hline & PQ5 & 4.62 & 1.48 & & \\
\hline & PQ6 & 5.64 & 1.11 & & \\
\hline & PQ7 & 5.94 & 0.97 & & \\
\hline \multirow[t]{5}{*}{ Hedonic Quality-Stimulation (HSQ) } & HSQ1 & 6.17 & 1.03 & .57 & .87 \\
\hline & HSQ2 & 5.90 & 1.22 & & \\
\hline & HSQ4 & 6.08 & 1.09 & & \\
\hline & HSQ5 & 6.12 & 1.06 & & \\
\hline & HSQ7 & 6.25 & 0.93 & & \\
\hline \multirow[t]{9}{*}{ Nausea $(\mathrm{N})$} & N1 & 0.29 & 0.55 & .14 & .46 \\
\hline & $\mathrm{N} 2$ & 0.15 & 0.36 & & \\
\hline & N3 & 0.37 & 0.59 & & \\
\hline & N4 & 0.09 & 0.29 & & \\
\hline & N5 & 0.24 & 0.48 & & \\
\hline & N6 & 0.17 & 0.41 & & \\
\hline & N7 & 0.08 & 0.27 & & \\
\hline & N8 & 0.16 & 0.42 & & \\
\hline & N9 & 0.03 & 0.24 & & \\
\hline
\end{tabular}




\begin{tabular}{|c|c|c|c|c|c|}
\hline \multirow[t]{7}{*}{ Oculomotor (OM) } & OM1 & 0.76 & 0.71 & .27 & .39 \\
\hline & $\mathrm{OM} 2$ & 0.17 & 0.43 & & \\
\hline & OM3 & 0.70 & 0.63 & & \\
\hline & OM4 & 0.26 & 0.53 & & \\
\hline & OM5 & 0.29 & 0.55 & & \\
\hline & OM6 & 0.33 & 0.52 & & \\
\hline & OM7 & 0.12 & 0.33 & & \\
\hline \multirow[t]{4}{*}{ Ability to act (AA) } & AA1 & 5.30 & 1.25 & .49 & .79 \\
\hline & AA2 & 6.02 & 0.93 & & \\
\hline & AA3 & 4.85 & 1.43 & & \\
\hline & AA4 & 5.48 & 1.23 & & \\
\hline \multirow[t]{2}{*}{ Ability to examine (AE) } & AE1 & 5.29 & 1.38 & .54 & .67 \\
\hline & AE3 & 5.02 & 1.31 & & \\
\hline \multirow[t]{3}{*}{ Interface quality (IQ) } & IQ1 & 5.90 & 1.23 & .53 & .77 \\
\hline & IQ2 & 5.19 & 1.36 & & \\
\hline & IQ3 & 5.24 & 1.38 & & \\
\hline \multirow[t]{2}{*}{ Self-Assessment of Performance (P) } & $\mathrm{P} 1$ & 5.58 & 1.27 & .77 & .87 \\
\hline & $\mathrm{P} 2$ & 4.91 & 1.40 & & \\
\hline \multirow[t]{7}{*}{ Realism (R) } & $\mathrm{R} 1$ & 4.45 & 1.38 & .42 & .83 \\
\hline & $\mathrm{R} 2$ & 5.42 & 1.23 & & \\
\hline & R3 & 4.51 & 1.44 & & \\
\hline & $\mathrm{R} 4$ & 4.74 & 1.59 & & \\
\hline & R5 & 4.48 & 1.07 & & \\
\hline & R6 & 4.98 & 1.47 & & \\
\hline & $\mathrm{R} 7$ & 6.07 & 0.93 & & \\
\hline \multirow[t]{4}{*}{ Personal Innovativeness (PI) } & PI1 & 3.80 & 1.85 & .77 & .93 \\
\hline & PI2 & 3.85 & 2.05 & & \\
\hline & PI3 & 5.08 & 1.94 & & \\
\hline & PI4 & 5.52 & 1.63 & & \\
\hline
\end{tabular}

Note. $\mathrm{AVE}=$ average variance extracted $\mathrm{CR}=$ composite reliability. 


\section{TABLE 2}

Correlation matrix and discriminant validity

\begin{tabular}{|c|c|c|c|c|c|c|c|c|c|c|c|c|c|}
\hline Constructs & $\mathrm{AA}$ & $\mathrm{AE}$ & PEOU & IU & IQ & NAU & OCULO & $\mathrm{P}$ & HQS & PQ & $\mathrm{R}$ & PI & PU \\
\hline $\mathrm{AA}$ & .70 & & & & & & & & & & & & \\
\hline $\mathrm{AE}$ & .54 & .73 & & & & & & & & & & & \\
\hline PEOU & .54 & .47 & .88 & & & & & & & & & & \\
\hline IU & .33 & .29 & .40 & .94 & & & & & & & & & \\
\hline IQ & .45 & .28 & .43 & .20 & .73 & & & & & & & & \\
\hline NAU & -.01 & .04 & -.18 & -.35 & -.07 & .38 & & & & & & & \\
\hline OCULO & -.25 & -.15 & -.27 & -.26 & -.13 & .14 & .43 & & & & & & \\
\hline $\mathrm{P}$ & .62 & .53 & .59 & .34 & .35 & -.11 & -.38 & .87 & & & & & \\
\hline HQS & .08 & .12 & .09 & .20 & .07 & .10 & -.16 & .13 & .75 & & & & \\
\hline $\mathrm{PQ}$ & .60 & .49 & .68 & .34 & .53 & -.16 & -.25 & .62 & .14 & .67 & & & \\
\hline $\mathrm{R}$ & .54 & .35 & .29 & .42 & .23 & .00 & -.24 & .56 & .41 & .34 & .65 & & \\
\hline PI & .42 & .19 & .35 & .41 & .28 & -.25 & -.06 & .34 & -.09 & .37 & .19 & .88 & \\
\hline PU & .35 & .39 & .34 & .44 & .30 & -.11 & -.23 & .39 & .41 & .33 & .45 & .26 & .81 \\
\hline
\end{tabular}

Note. Values on the diagonal represent the square root of average variance extracted for a construct.

$\mathrm{AA}=$ ability to act $\mathrm{AE}=$ ability to examine; $\mathrm{PEOU}=$ perceived ease of use; $\mathrm{IU}=$ intention to use; $\mathrm{IQ}=$ interface quality; $\mathrm{NAU}=$ nausea;

OCULO = oculomotor; $\mathrm{P}=$ performance; $\mathrm{HQS}=$ hedonic quality-stimulation; $\mathrm{PQ}=$ pragmatic quality; $\mathrm{R}=$ realism; $\mathrm{PI}=$ personal

innovativeness; $\mathrm{PU}=$ perceived usefulness. 


\section{TABLE 3}

HTMT (Heterotrait-monotrait ratio of correlations) results

\begin{tabular}{|c|c|c|c|c|c|c|c|c|c|c|c|c|c|}
\hline Constructs & AA & $\mathrm{AE}$ & PEOU & IU & IQ & NAU & OCULO & $\mathrm{P}$ & HQS & PQ & $\mathrm{R}$ & PI & PU \\
\hline \multicolumn{14}{|l|}{ AA } \\
\hline $\mathrm{AE}$ & 1.31 & & & & & & & & & & & & \\
\hline IU & 0.44 & 0.57 & 0.45 & & & & & & & & & & \\
\hline IQ & 0.76 & 0.74 & 0.61 & 0.28 & & & & & & & & & \\
\hline NAU & 0.42 & 0.54 & 0.28 & 0.25 & 0.40 & & & & & & & & \\
\hline $\mathrm{P}$ & 0.92 & 1.17 & 0.75 & 0.42 & 0.57 & 0.33 & 0.60 & & & & & & \\
\hline HQS & 0.23 & 0.30 & 0.21 & 0.19 & 0.19 & 0.33 & 0.29 & 0.16 & & & & & \\
\hline PQ & 0.86 & 0.97 & 0.81 & 0.41 & 0.78 & 0.41 & 0.58 & 0.84 & 0.24 & & & & \\
\hline $\mathrm{R}$ & 0.75 & 0.89 & 0.33 & 0.48 & 0.41 & 0.34 & 0.37 & 0.71 & 0.49 & 0.45 & & & \\
\hline PI & 0.51 & 0.31 & 0.35 & 0.44 & 0.36 & 0.29 & 0.17 & 0.44 & 0.17 & 0.44 & 0.24 & & \\
\hline PU & 0.48 & 0.89 & 0.38 & 0.51 & 0.43 & 0.26 & 0.23 & 0.47 & 0.45 & 0.40 & 0.54 & 0.29 & \\
\hline
\end{tabular}

Note. The two results marked in bold are greater than the recommended threshold value of 1 .

$\mathrm{AA}=$ ability to act $\mathrm{AE}=$ ability to examine; $\mathrm{PEOU}=$ perceived ease of use; $\mathrm{IU}=$ intention to use; $\mathrm{IQ}=$ interface quality; $\mathrm{NAU}=$ nausea;

OCULO = oculomotor; $\mathrm{P}=$ performance; $\mathrm{HQS}=$ hedonic quality-stimulation; $\mathrm{PQ}=$ pragmatic quality; $\mathrm{R}=$ realism; $\mathrm{PI}=$ personal

innovativeness; $\mathrm{PU}=$ perceived usefulness. 


\section{TABLE 4}

Weights, significance of the weights and loadings of the first-order constructs

\begin{tabular}{ccccc}
\hline Second-order & First-order constructs & Weights & Loadings & $t$ \\
constructs & & & & \\
\hline Presence & Ability to act & .09 & .73 & 0.29 \\
& Ability to examine & .24 & .63 & 0.85 \\
& Interface quality & .11 & .43 & 0.59 \\
& Self-assessment of performance & .13 & .74 & 0.52 \\
& Realism & .69 & .92 & $3.10^{* *}$ \\
Cybersickness & Nausea & .80 & .87 & $3.57^{* *}$ \\
& Oculomotor & .50 & .61 & $1.96^{*}$ \\
\hline
\end{tabular}

Note. ${ }^{*} p<.05 ; * * p<.01$ 
TABLE 5

Structural model results

\begin{tabular}{|c|c|c|c|c|}
\hline Hypothesis & Path & $\begin{array}{l}\text { Path } \\
\text { coefficient }\end{array}$ & $t$ & $\begin{array}{l}\text { Supported or } \\
\text { not }\end{array}$ \\
\hline H1 & $\mathrm{PEOU} \rightarrow \mathrm{IU}$ & .09 & 0.76 & No \\
\hline $\mathrm{H} 2$ & $\mathrm{PU} \rightarrow \mathrm{IU}$ & .20 & $1.96 *$ & Yes \\
\hline H3 & $\mathrm{PEOU} \rightarrow \mathrm{PU}$ & .16 & 0.97 & No \\
\hline $\mathrm{H} 4 \mathrm{a}$ & $\mathrm{PQ} \rightarrow \mathrm{PEOU}$ & .64 & $8.01 * *$ & Yes \\
\hline $\mathrm{H} 4 \mathrm{~b}$ & $\mathrm{PQ} \rightarrow \mathrm{PU}$ & .11 & 0.72 & No \\
\hline H5a & $\mathrm{HQS} \rightarrow \mathrm{PEOU}$ & .01 & 0.10 & No \\
\hline $\mathrm{H} 5 \mathrm{~b}$ & $\mathrm{HQS} \rightarrow \mathrm{PU}$ & .40 & $2.85^{* *}$ & Yes \\
\hline H6 & $\mathrm{CS} \rightarrow \mathrm{IU}$ & -.26 & $2.53 *$ & Yes \\
\hline $\mathrm{H} 7$ & $\mathrm{PSC} \rightarrow \mathrm{IU}$ & .22 & 1.86 & No \\
\hline $\mathrm{H} 8 \mathrm{a}$ & $\mathrm{PI} \rightarrow \mathrm{PEOU}$ & .10 & 1.18 & No \\
\hline $\mathrm{H} 8 \mathrm{~b}$ & $\mathrm{PI} \rightarrow \mathrm{PU}$ & .20 & $2.05 *$ & Yes \\
\hline $\mathrm{H} 8 \mathrm{c}$ & $\mathrm{PI} \rightarrow \mathrm{IU}$ & .20 & 1.81 & No \\
\hline
\end{tabular}

Note. PEOU = perceived ease of use; $\mathrm{IU}=$ intention to $\mathrm{use} ; \mathrm{PU}=$ perceived usefulness;

$\mathrm{PQ}=$ pragmatic quality; HQS = hedonic quality-stimulation; $\mathrm{CS}=$ cybersickness; PSC

$=$ presence $; \mathrm{PI}=$ personal innovativeness .

$* p<.05 ; * * p<.01$ 
Figures

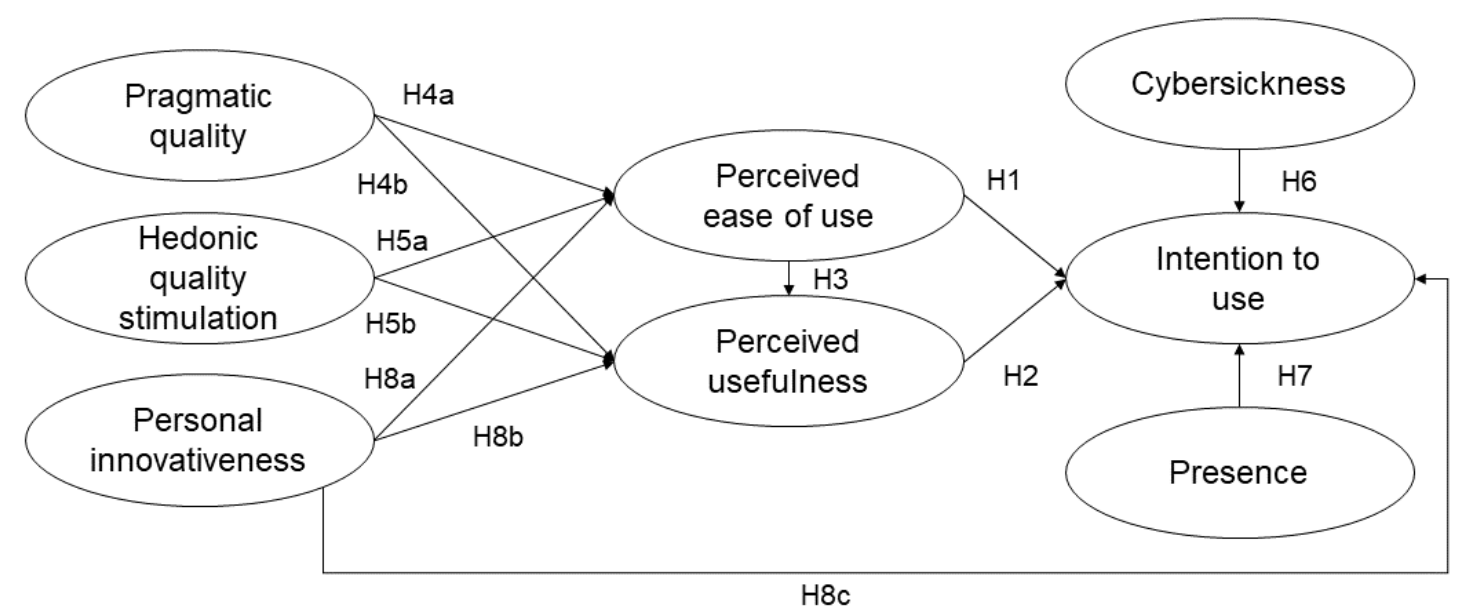

Figure 1

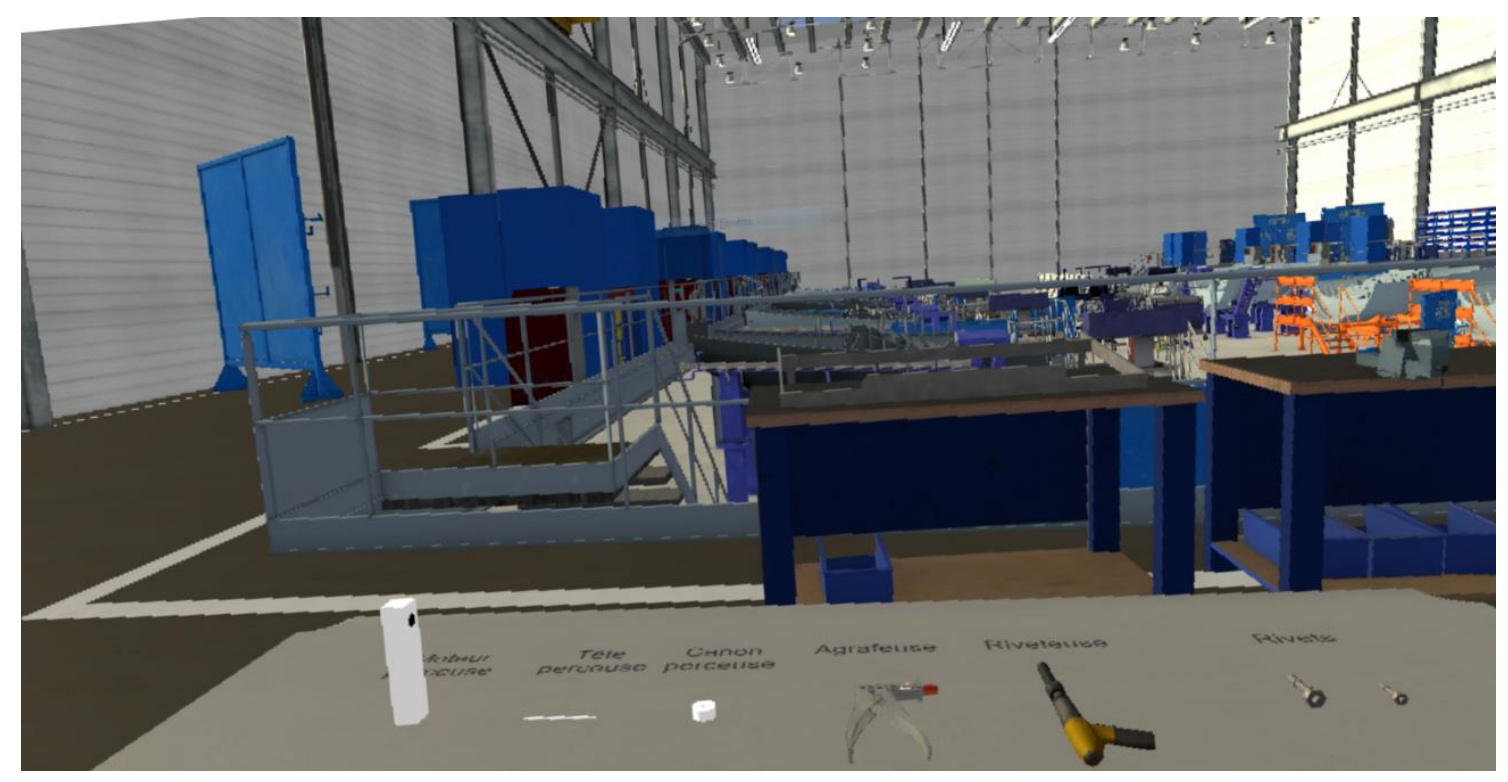

Figure 2 


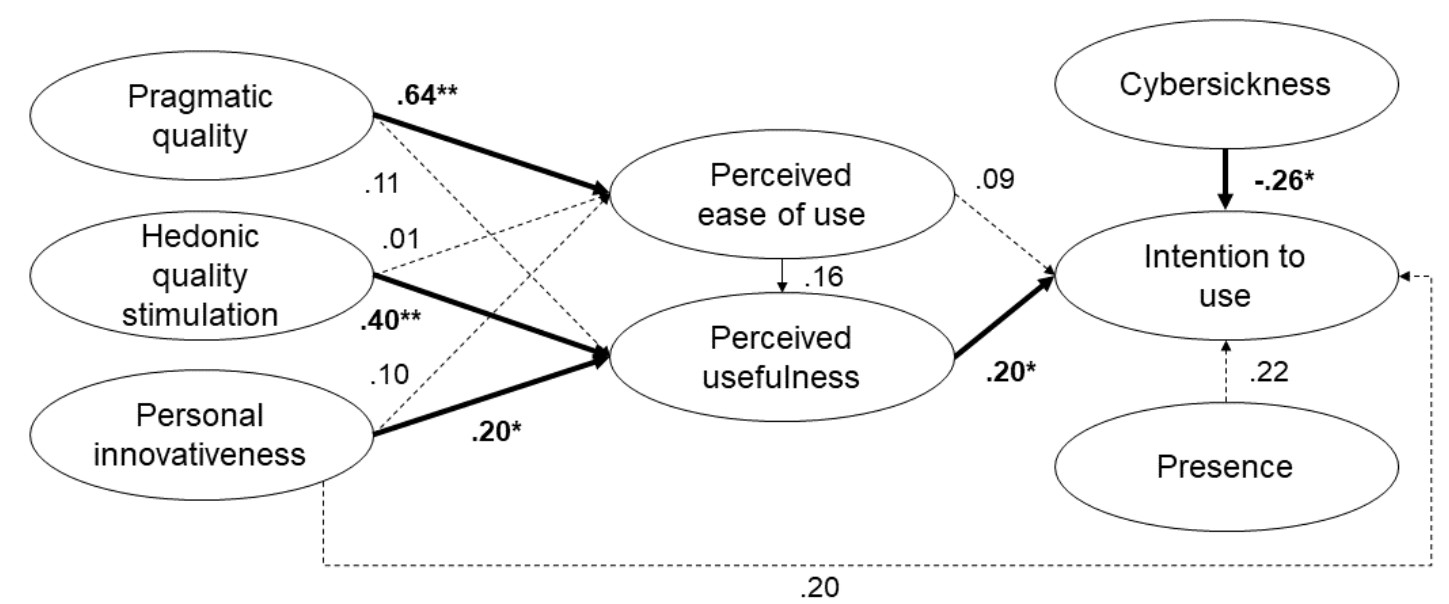

Figure 3 
Figure captions

- Figure 1. The research model depicting the relationship between the variables investigated in the study

- Figure 2. Screenshot of the virtual environment

- Figure 3. Model estimation results 